\title{
Accurate Study and Evaluation of Small PV Power Generation System Based on Specific Geographical Location
}

\author{
Lian Zhang ${ }^{1,2,3,5, *}$, Zijian Chen ${ }^{2}$, Heng Zhang ${ }^{3}$, Zenghong $\mathrm{Ma}^{4}$, Baowen $\mathrm{Cao}^{1}$ and Lihong Song ${ }^{5}$ \\ ${ }^{1}$ Basic Experimental and Training Center, Tianjin Sino-German University of Applied Sciences, Tianjin, 300350, China \\ ${ }^{2}$ School of Energy Engineering, Tianjin Sino-German University of Applied Sciences, Tianjin, 300350, China \\ ${ }^{3}$ College of Mechanical Engineering, Tianjin University of Science \& Technology, Tianjin, 300222, China \\ ${ }^{4}$ Basic Courses Department, Tianjin Sino-German University of Applied Sciences, Tianjin, 300350, China \\ ${ }^{5}$ Tianjin Qicheng Science \& Technology Co., Ltd., Tianjin, 300193, China \\ ${ }^{*}$ Corresponding Author: Lian Zhang. Email: zhanglian@tsguas.edu.cn \\ Received: 31 July 2020; Accepted: 26 August 2020
}

\begin{abstract}
As an important new energy, solar energy has been extensively used in the world and different types of solar energy systems have been used in different fields. The photovoltaic power generation system has obvious advantage and high stability compared with other energy systems. Furthermore, the small-scale photovoltaic power generation system has a wider application in the field of power generation due to the performance of high efficiency. In this paper, the optimization research and system evaluation of small-scale photovoltaic power system have been studied in different areas by simulation and experimental methods. Based on the determination of photovoltaic model system, four typical geographical locations are selected and PVsyst is applied to the simulation study. The annual power output is $4829 \mathrm{kWh}, 3489 \mathrm{kWh}, 4455 \mathrm{kWh}, 2766 \mathrm{kWh}$ and the solar energy utilization efficiency is $14.91 \%, 14.79 \%, 17.66 \%, 15.77 \%$ for Mexico City, Xinyang, Changchun and London respectively from the simulation results. The results show that the radiation conditions, the optimum tilt angle, the minimum spacing and different geographical locations are the main reasons for the difference of power generation and solar energy utilization efficiency. Subsequently, Changchun is selected as the experimental area to carry out experimental research and verify the conclusion of the simulation study. The volt ampere characteristic curve and power output curve show that the photovoltaic system has no defects, hot spots, partial shading and damage. The annual total power generation of Changchun is $4119 \mathrm{kWh}$. Hence, the simulation results are in good agreement with the experimental results. Consequently, the application of small photovoltaic power generation system requires to fully consider the regional conditions and key parameters (optimum tilt angle, minimum spacing, etc.) to obtain better power generation efficiency.
\end{abstract}

Keywords: Power generation; small photovoltaic system; optimum tilt angle; minimum spacing

This work is licensed under a Creative Commons Attribution 4.0 International License, which permits unrestricted use, distribution, and reproduction in any medium, provided the original work is properly cited. 


\section{Introduction}

New energy is one of the inevitable choices to solve the problems of environmental pollution, ozone layer destruction, greenhouse gas emissions, energy demand shortage, etc. The new energy includes solar energy, wind energy, biomass energy, etc. With the continuous development of new energy industry recently, solar energy has been more and more recognized and adopted by humans because of its advantages of rich, clean, safe and sustainable utilization. It has a broad application prospect to provide energy for people and bring convenience to life at the same time. The lack of power supply and low-cost power demand in the world are driving the development of photovoltaic power generation. Photovoltaic power generation is more convenient and could provide power for medical treatment, education, communication, lighting, water conservancy and agriculture in areas rich in solar energy resources. With the continuous development of science, technology and economy, the photovoltaic industry is also constantly upgrading and optimizing. The traditional mainstream large-scale photovoltaic power plants have limited capacity improvement and low power generation efficiency due to the phenomenon of light abandonment and significant energy loss. The photovoltaic system with small capacity and special purpose is more and more popular. Many researchers are carrying out some relative researches in the field of above solar energy system.

The removeable and small-scale photovoltaic power generation system could meet the demand of highly efficient power generation and flexible utilization. A mobile photovoltaic hybrid system for remote areas had been designed by Krisada et al. [1]. This unit built in an easy way to move container unit. A series of experiments results showed that the system could worked normally because of the design and stability of power supply. A mobile, renewable home with a photovoltaic/wind/fuel cell hybrid system had been tested by Mehmed et al. [2]. As an independent power system in remote areas, mobile houses generated enough power to meet the peak load in specific situations such as natural disasters. Photovoltaic and wind power were used for the main power supply in the mobile residential system. The key performance index (KPI) of grid connected photovoltaic system under the weather conditions in Suriname had been calculated and compared with the expected value using PVsyst by Amrita et al. [3].

In the meantime, the photovoltaic power generation system has obvious advantages for some remote places such as rural areas, oceans, ships, etc. Different types of the wind, photovoltaic and diesel hybrid systems for a village in the northeast had been designed by Rehman et al. [4]. Among them, the hybrid Saudi Arabian administrative zoning system based on local average wind speed per hour, total solar radiation per hour and hourly load data had been optimized. The potential of a floating photovoltaic system on a mine Lake in South Korea had been analyzed by Song et al. [5]. The layout design of the floating photovoltaic system took into account the optimal tilt angle and array spacing of photovoltaic panels. In view of the application of photovoltaic array in ships, the application characteristics of photovoltaic array and its components in ships were analyzed by Chen et al. [6] on the basis of the introduction of the principle and method of photovoltaic array utilization. This study discussed and summarized the important characteristics of marine power grid on the basis of photovoltaic array which provided a reference for future system design and application. Taking large ocean-going ships as the research object, the application of distributed photovoltaic power generation in ship power generation system had been studied by Yang et al. [7] and the corresponding model was established.

However, some core parameters are the key places to improve the efficiency and optimize the setting of photovoltaic power generation system. The optimum tilt angle of photovoltaic systems had been studied by Yong et al. [8]. The results found that an oriental oriented module provided the largest tilt exposure to Singapore's climate conditions in each year. The evaluation of PV modules and optimal tilt angle for all over the world had been launched by Mark et al. [9]. The results showed that 1-axis horizontal tracking, except for the highest latitude, was recommended to use in order to obtain the higher efficiency. The optimum tilt angle, solar radiation and performance of BIPV thermal system had been assessed by 
introducing corresponding shadow effects by Yadav et al. [10]. The variation of the width (b), floor height (h) and horizontal distance (d) of these surrounding buildings were considered in this study. The results showed that the performance of the BIPV system was affected by shading and sky view blocking. The influence of the orientation of photovoltaic modules and optimum tilt angle on the performance of rural PV system was studied by Sunderan et al. [11]. The results indicated that the orientation of photovoltaic modules was as important as the optimum tilt angle. The theoretical calculation and experimental results of the variation characteristics of the surface irradiance of silicon photovoltaic array were compared by Kuvshinov et al. [12]. A method for the MPPT of the PV module with some shading was proposed by Tobón et al. [13] and the simulation and experimental research were conducted to demonstrate this method. The results showed that the proper MPPT with IPSM algorithm had a faster response. An optimized DE algorithm by researching the output characteristics of PV module under partial shading conditions was carried out by Zhang et al. [14]. The results showed that the proposed algorithm had a higher convergence speed and less steady-state oscillation loss by the simulation research.

Mathematical modeling is an important part for any scientific research. The modeling and design of photovoltaic power generation system also plays a critical role for the subsequent experimental research and practical engineering application. Nowadays, many kinds of software have been applied to the photovoltaic system. With its advantages of specialization, modularization and systematization, PVsyst has been favored by researchers and engineers all over the world and a series of researches have been carried out with it. PVsyst had been applied to model the irradiance and temperature dependence of photovoltaic module by Sauer et al. [15]. Two methods had been developed to fit the temperature dependence of module power in PVsyst and applied to the latest multi-irradiance and temperature data of standard Yingli PV module types. The results showed that it could matched the measured irradiance and temperature dependence of PV module by PVsyst. PVsyst had been used for the design of PV power system by Odeh [16] in the study of thermal performance of dwellings with rooftop PVT module. This software had been mainly applied to evaluate the power generation of the roof photovoltaic system too. The performance of national photovoltaic projects in India had been evaluated by Purohita et al. [17]. PVsyst had been adopted to evaluate the energy income of photovoltaic projects in consideration of the key design and technical parameters of photovoltaic system and the related energy loss in the process of solar energy conversion.

The authors also had some works in the field of the photovoltaic system and got some achievements recently. They have paid more attention to the small-scale and removeable photovoltaic power generation system and the hybrid solar energy system and its application. A mobile photovoltaic hybrid system was proposed by Zhang et al. [18] from the aspects of structure, control system, electrical flow and heat flow. The experimental results showed that the system generated $691 \mathrm{kWh}$ of electric energy and $3047.8 \mathrm{kWh}$ of heat energy every year under normal conditions. A floor radiant heating system based on photovoltaic and solar thermal technology had been analyzed by Zhang et al. [19]. The calculation method of this system and this heating system were applied to the actual heating system. A solar dedicated ventilation system based on ADRC had been also proposed by Zhang et al. [20]. Through the experimental research, higher control accuracy and energy saving potential were obtained compared with the conventional system. This is the basic condition for the smooth development of this study.

According to the analysis of the above studies, this study finds that the current photovoltaic system often has the characteristics of mobility, small capacity, specific needs. It also has very strict requirements for the mutual position between the sunlight and the photovoltaic system, the site where the system is located, the setting of core parameters and the specific installation mode of the system. These researches indicate that the authors' previous work on small capacity solar systems also need to take into account the impact of location. Therefore, the main work of this study will establish a small capacity photovoltaic model system, then use the PVsyst to simulate specific needs and different geographical locations for this photovoltaic system and build 
the experimental system and measure the data according to the simulation results at last. Some general conclusions of this study will provide the basis for the research and evaluation of the small-scale photovoltaic power generation system.

\section{Model System}

\subsection{Model System and Parameter}

A model system has been established in the first step of this study. The main model parameters which involve the size of the module, the optimum tilt angle according to the location, the sun altitude angle and the minimum spacing between photovoltaic modules will be considered for the photovoltaic system. The optimal inclination, minimum spacing and other main parameters of PV module which will be applied to the model system are shown in Fig. 1. These parameters have different values in different geographical locations to achieve the optimal power generation. The size of the standard photovoltaic module is constant, but the solar altitude angle and the optimum tilt angle will vary based on the regional location. The minimum spacing $(D)$ is the minimum distance between photovoltaic module without shading and it could minimize the total areas of the photovoltaic system. The minimum spacing between photovoltaic modules could be calculated by the Eqs. (1)-(6):

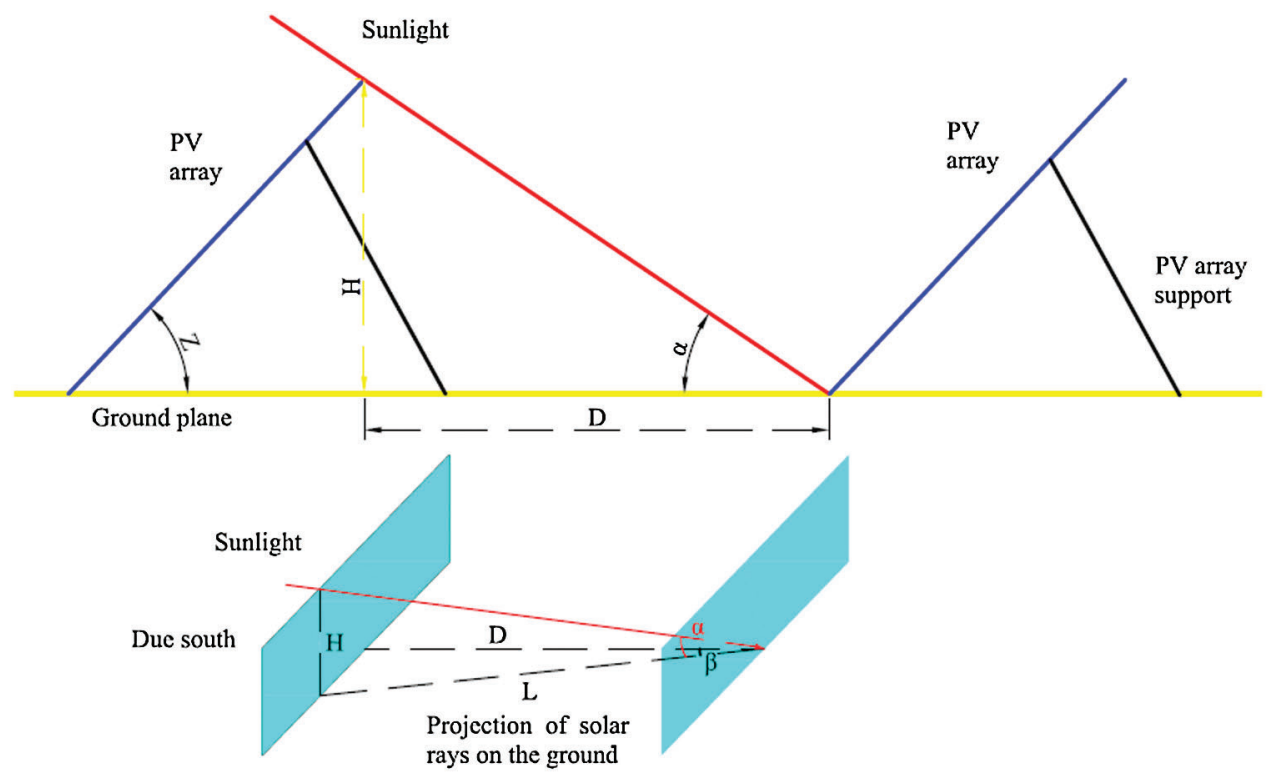

Figure 1: Schematic diagram of optimal inclination, minimum spacing and main parameters of PV module for model system

$D=\cos \beta \cdot L$

$L=H / \tan \alpha$

$\sin \beta=\cos \delta \cdot \sin \omega / \cos \alpha$

$\sin \alpha=\sin \phi \sin \delta+\cos \phi \cos \delta \cos \omega$

$\alpha=\arcsin (\sin \phi \sin \delta+\cos \phi \cos \delta \cos \omega)$

$\sin \delta=0.39795 \cdot \cos [0.98563(n-173)]$ 
where:

$H$ : Height of PV module, m;

$\alpha$ : Solar altitude angle ${ }^{\circ}$;

$D$ : Minimum spacing, $\mathrm{m}$;

$L$ : Projection of solar rays on the ground, m;

$\beta$ : Sun azimuth, ${ }^{\circ}$;

$\delta$ : Solar declination angle, ${ }^{\circ}$;

$\phi$ : Local latitude, ${ }^{\circ}$;

$\omega$ : Hour angle, take $0^{\circ}$ at noon, $180^{\circ}$ at midnight, $90^{\circ}$ at $6: 00$ and $18: 00,45^{\circ}$ at 9:00 and 15:00;

$n$ : Days, calculated from January 1.

When the total solar irradiation on the inclined plane of photovoltaic module is maximum, the angle between photovoltaic modules and ground plane is the optimum tilt angle $(Z)$. The optimum tilt angle of photovoltaic module is generally related to the location of photovoltaic system. In general, the total solar irradiation on the inclined plane of photovoltaic module could be represented by the scattering irradiation, ground reflection irradiation and direct irradiation Thus, the hourly total solar irradiation on the inclined plane for the photovoltaic module could be obtained by follow equations:

$G_{t t}(i)=G_{b t}(i)+G_{d t}(i)+G_{r}(i)$

where:

$G_{t t}(i)$ : Total solar irradiation on the inclined plane of photovoltaic module at $i$ time, $W /\left(\mathrm{m}^{2} \cdot h\right)$;

$G_{b t}(i)$ : Direct solar irradiation on the inclined plane of photovoltaic module at $i$ time, $W /\left(m^{2} \cdot h\right)$;

$G_{d t}(i)$ : Scattering irradiation of solar radiation on the inclined plane of photovoltaic module at $i$ time, $W /\left(m^{2} \cdot h\right)$;

$G_{r}(i)$ : Reflection of solar irradiation on the inclined surface of photovoltaic module at $i$ time, $W /\left(m^{2} \cdot h\right)$.

For a certain azimuth, the optimum tilt angle could be obtained by the following equation:

$\frac{d}{d Z}\left[\sum_{i=1}^{m} G_{t t}(i)\right]_{Z_{o p t}}=0$

where:

$m$ : The total number of hours in the calculation process, take 8760 for the whole year, 2160 for three months and 720 for one month.

The direct sunlight on the inclined surface of photovoltaic module $G_{b t}$ could be expressed as:

$G_{b t}=G_{b h} \cdot \frac{\cos \theta}{\cos \theta_{z}}=G_{b h} \cdot R_{b}$

where:

$G_{b h}$ : Direct solar irradiation that can be obtained on the horizontal plane, $W /\left(m^{2} \cdot h\right)$;

$\theta$ : Incidence angle, the direction angle between the direct irradiation incident on a surface and the normal direction of the surface, ${ }^{\circ}$;

$\theta_{z}$ : Incident angle of horizontal plane, also known as the zenith angle of the sun, ${ }^{\circ}$; 
$R_{b}$ : Shape factor.

The following equation could be used for the determination of the incident angle:

$$
\begin{aligned}
\cos \theta= & \sin \delta \sin \phi \cos Z-\sin \delta \cos \phi \sin Z \cos \gamma+\cos \delta \cos \phi \cos Z \cos \omega \\
& +\cos \delta \sin \phi \sin Z \cos \gamma \cos \omega+\cos \delta \sin Z \sin \gamma \sin \omega \\
\cos \theta_{z}= & \cos \delta \cos \phi \cos \omega+\sin \delta \sin \phi
\end{aligned}
$$

where:

$\delta$ : The tilt angle of the sun, $-23.45^{\circ} \leq \delta \leq 23.45^{\circ},{ }^{\circ}$;

$\phi$ : Local latitude, ${ }^{\circ}$;

$\gamma$ : Azimuth of photovoltaic module, take 0 for the south, negative for the East and positive for the West, $-180^{\circ} \leq \gamma \leq 180^{\circ},{ }^{\circ}$;

$\omega$ : Hour angle, take negative in the morning and positive in the afternoon.

The tilt angle of the sun could be expressed as:

$\delta=23.45 \sin \left(360 \times \frac{284+n}{365}\right)$

where:

$n$ : Day, The nth day of the year, value: 1-365.

The reflected part of the ground on the inclined plane for the photovoltaic module could be expressed as follows:

$G_{r}=\frac{\rho o}{2} \cdot G_{t h} \cdot(1-\cos Z)$

where:

$G_{t h}$ : Total solar irradiation on the horizontal plane, $W /\left(m^{2} \cdot h\right)$;

$\rho_{\mathrm{o}}$ : Ground reflection coefficient, the reflection coefficient of snow surface could be set as 0.6 and the reflection coefficient of snow free ground could be determined as 0.2 .

The solar scattering on the inclined plane of photovoltaic module could be calculated by Reindl model:

$G_{d t}=G_{d h} \cdot \cos ^{2}\left(\frac{Z}{2}\right) \cdot\left(1-A_{1}\right)\left[1+f \cdot \sin ^{3}\left(\frac{Z}{2}\right)\right]+G_{d h} \cdot A_{1} \cdot R_{b}$

where:

$G_{d h}$ : Scattering irradiation on the horizontal plane, $W /\left(m^{2} \cdot h\right)$.

$A_{1}=\frac{G_{b n}}{G_{o n}}=\frac{G_{b h} / \cos \theta_{z}}{G_{0} / \cos \theta_{z}}=\frac{G_{b h}}{G_{0}}$

$f=\sqrt{\frac{G_{b h}}{G_{t h}}}$

where: 
$G_{0}$ : The solar irradiation that could be obtained on the horizontal plane of the outer atmosphere which could be expressed:

$G_{0}=G_{s c}\left[1+0.033 \cos \left(\frac{360 n}{365}\right)\right](\cos \delta \cos \phi \cos \omega+\sin \delta \sin \phi)$,
where:

$G_{s c}$ : Constant, around $1353 \mathrm{~W} / \mathrm{m}^{2}$.

$n$ : Day, calculated from January 1.

The optimum tilt angle and the minimum spacing could be calculated according to the above mathematical formula.

\subsection{Calculation and Analysis}

Four representative geographical locations in the world have been selected after determining the photovoltaic model system in this study. The photovoltaic power generation system with the highest efficiency and the smallest total areas could be gained by the optimum tilt angle and the minimum spacing. So, the optimum tilt angle and minimum spacing of different regions could be calculated by the Eqs. (1)-(16). The results of optimum tilt angle and minimum spacing for four typical cities of this study are shown in Tab. 1.

Table 1: Optimum tilt angle, minimum spacing and four typical geographic locations information

\begin{tabular}{llllll}
\hline No. & City & Longitude $\left({ }^{\circ}\right)$ & Latitude $\left({ }^{\circ}\right)$ & Optimum tilt angle $\left(^{\circ}\right)$ & $D(\mathrm{~m})$ \\
\hline 1 & Mexico City & -99.2 & 19.4 & 14.3 & 2.6 \\
2 & Xinyang & 115.7 & 32.2 & 29.2 & 4 \\
3 & Changchun & 125.2 & 43.9 & 46.3 & 7.3 \\
4 & London & -0.1 & 51.5 & 59.6 & 15.5 \\
\hline
\end{tabular}

The results show that the four typical cities have a significant value for the following study. The longitude and latitude of the four cities could generally cover the typical photovoltaic application cities in the world and have a certain representativeness. The application of small photovoltaic power generation systems represented by these four cities have broad popularization and use prospect in America, Asia and Europe. It is difficult to judge the influence of terrain and longitude on power generation efficiency due to the strong solar irradiation and higher power generation of the photovoltaic system than other places in low latitude areas. However, high latitude areas are far beyond the Tropic of Capricorn and Cancer. These regions will never be able to get direct sunlight and the possibility of construction for photovoltaic system is smaller than other places. So, the latitude changes from $20^{\circ}$ to $51^{\circ}$ and optimum tilt angle ranges from $15^{\circ}$ to $60^{\circ}$ have been chosen in this study and the four cities have been selected for this study. These scopes of latitude and optimum tilt angle are suitable for photovoltaic system and have a higher power generation efficiency. The above data information provides the basic basis for the follow-up simulation and experimental research of this study.

The software of PVsyst is used for simulation to evaluate the power generation situation and power differences caused by different geographical locations in Chapter 3. The proposed system is tested according to the simulation results subsequently. The actual power generation is measured and calculated under the optimum tilt angle and minimum spacing. 


\section{Simulation Based on PVsyst}

PVsyst is a popular software which has been widely used for the simulation and design of the photovoltaic system all over the world. The PVsyst is an auxiliary software for the design of photovoltaic system and could be used for the simulation research of power generation for photovoltaic system. The PVsyst could complete the research, design and data analysis for photovoltaic system. The results obtained by this software could be used for reference by researchers and engineers. PVsyst is also a professional software which includes most of the main modules required only for PV system. The PVsyst involves the following functions:

a) Set the type of photovoltaic system: on-grid, off-grid, photovoltaic pump and so on;

b) Set the layout parameters of photovoltaic module: fixed mode, PV array tilt angle, line spacing, azimuth and so on;

c) Evaluate the influence of buildings on the shading for photovoltaic system and calculate the shading time and proportion;

d) Simulate the power generation capacity and efficiency for different types of photovoltaic systems;

e) Study the environmental parameters of photovoltaic system.

Nevertheless, other software like System Advisor Model (SAM) and Transient System Simulation Program (TRNSYS) are only used for scientific research which not conducive to engineering practice and promotion. Consequently, the PVsyst will be chosen for the simulation in this study. The layout parameters of photovoltaic module and the power generation of the photovoltaic system will be simulated by this software.

\subsection{Model Setting}

The PVsyst is applied to simulate and analyze the photovoltaic system of four typical cities in this study and the simulated site conditions of four regions are chosen for the simulation. The weather information map of four different regions could be gained and the array mode of photovoltaic module are set in each region according to the selected cities. The rated power of the photovoltaic system is $3 \mathrm{~kW}$ and the optimum tilt angle of the four regions are set as $15^{\circ}, 30^{\circ}, 45^{\circ}$ and $60^{\circ}$ respectively.

If the size of the proposed system increase, the optimum tilt angle and minimum spacing of photovoltaic module remain unchanged, the total areas increase and the annual power generations increase too. However, with the increase of the size, the equipment of the system become larger and the energy loss of the proposed system also increase. Therefore, the annual power generation will not increase geometrically and a certain loss must be existed. So, $3 \mathrm{~kW}$ system is adopted in this study.

The photovoltaic array model is carried out in this study. The width of the module is set as $1 \mathrm{~m}$ and the vertical height is set as $0.5 \mathrm{~m}$. The minimum spacing of photovoltaic modules for four regions are set as 2.6 , 4.0, 7.3, and 15.5 respectively according to the calculation results in Tab. 1. The setting interface and modeling effect are shown in Fig. 2.

Because of the different angles in different regions, the shading loss in each region are $0.5 \%, 1.7 \%$, $2.2 \%, 2.4 \%$ respectively in this study. The energy loss caused by shading and its influence on the solar horizon line are shown in Fig. 3. Therefore, it could be found that the energy loss in four regions is less after reasonable parameter setting. It basically covers all periods of solar radiation on the horizon line which shows that the setting of tilt angle and array mode is reasonable at the same time.

The detailed setting: The standard module is adopted for the PV module, the polycrystalline silicon cell is selected for the solar panel, the flat roof is selected for the installation position and the ventilation is free. The setting method is the same for different regions and the specific setting method is shown in Fig. 4. 


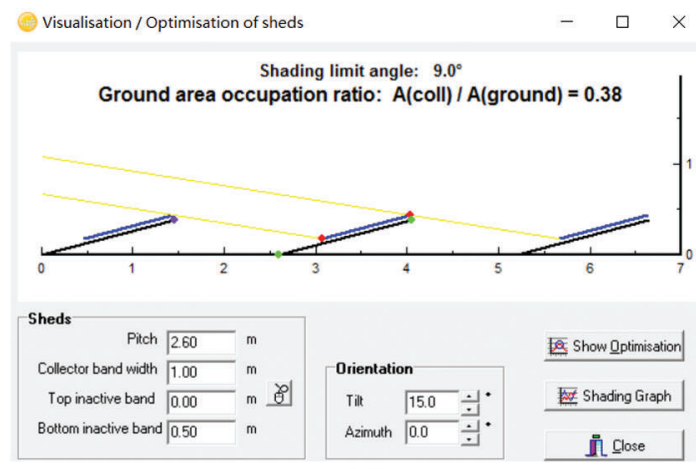

(a)

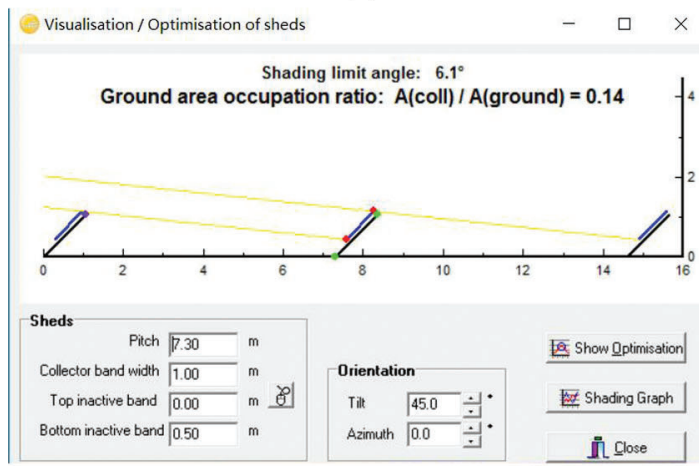

(c)

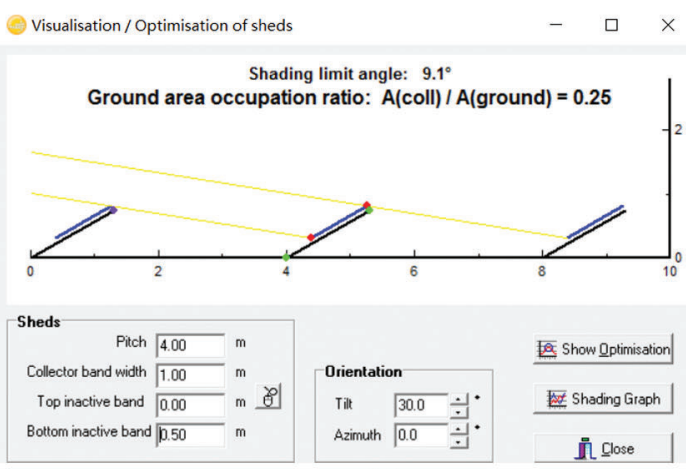

(b)

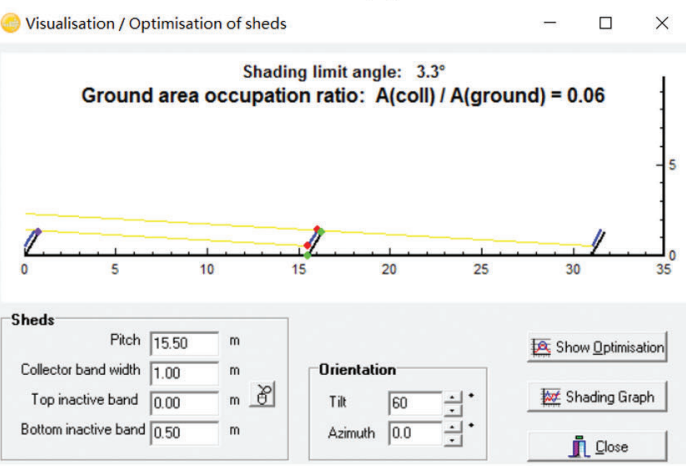

(d)

Figure 2: The setting interface and modeling effect of photovoltaic array. (a) Mexico City, (b) Xinyang, (c) Changchun, (d) London

\subsection{Results and Analysis}

The results involve the solar radiation conditions in different regions and the power generation of photovoltaic system which are simulated by the PVsyst after the detailed setup. The average daily irradiation per unit area of each month and the whole year on the horizontal plane, the average daily irradiation per unit area of each month and the whole year on the corresponding tilted plane and the average daily irradiation per unit area of each month and the whole year after considering the shading loss for each region are shown in Fig. 5. It could be found that the average daily irradiation per unit area of the whole year after considering the shading loss is higher than the average daily irradiation per unit area of the whole year on the horizontal plane. The simulation results show that the optimal layout of photovoltaic array enables the PV module to obtain more effective solar radiation.

The monthly and annual average daily power outputs of different regions are shown in Fig. 6 . The annual power outputs are $4829 \mathrm{kWh}, 3489 \mathrm{kWh}, 4455 \mathrm{kWh}$ and $2766 \mathrm{kWh}$, respectively. The radiation conditions and simulation output results of the four regions are summarized in Tab. 2. At the same time, the solar energy utilization efficiency which compare the annual power output with the annual solar irradiance of four areas also be calculated and listed in Tab. 2. 

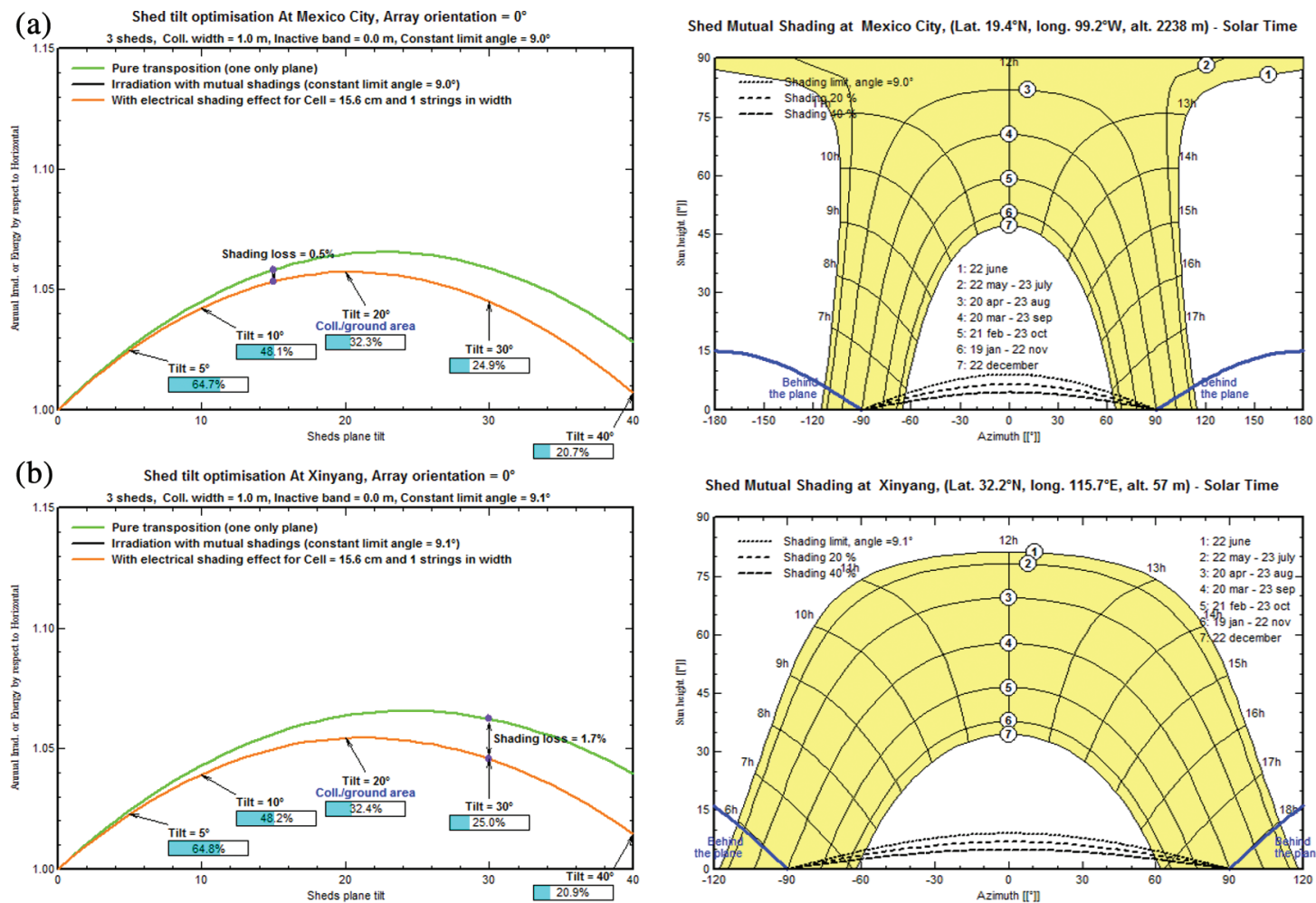

Shed Mutual Shading at Xinyang, (Lat. 32.2 $\mathrm{N}$, long. $115.7^{\circ} \mathrm{E}$, alt. $57 \mathrm{~m}$ ) - Solar Time
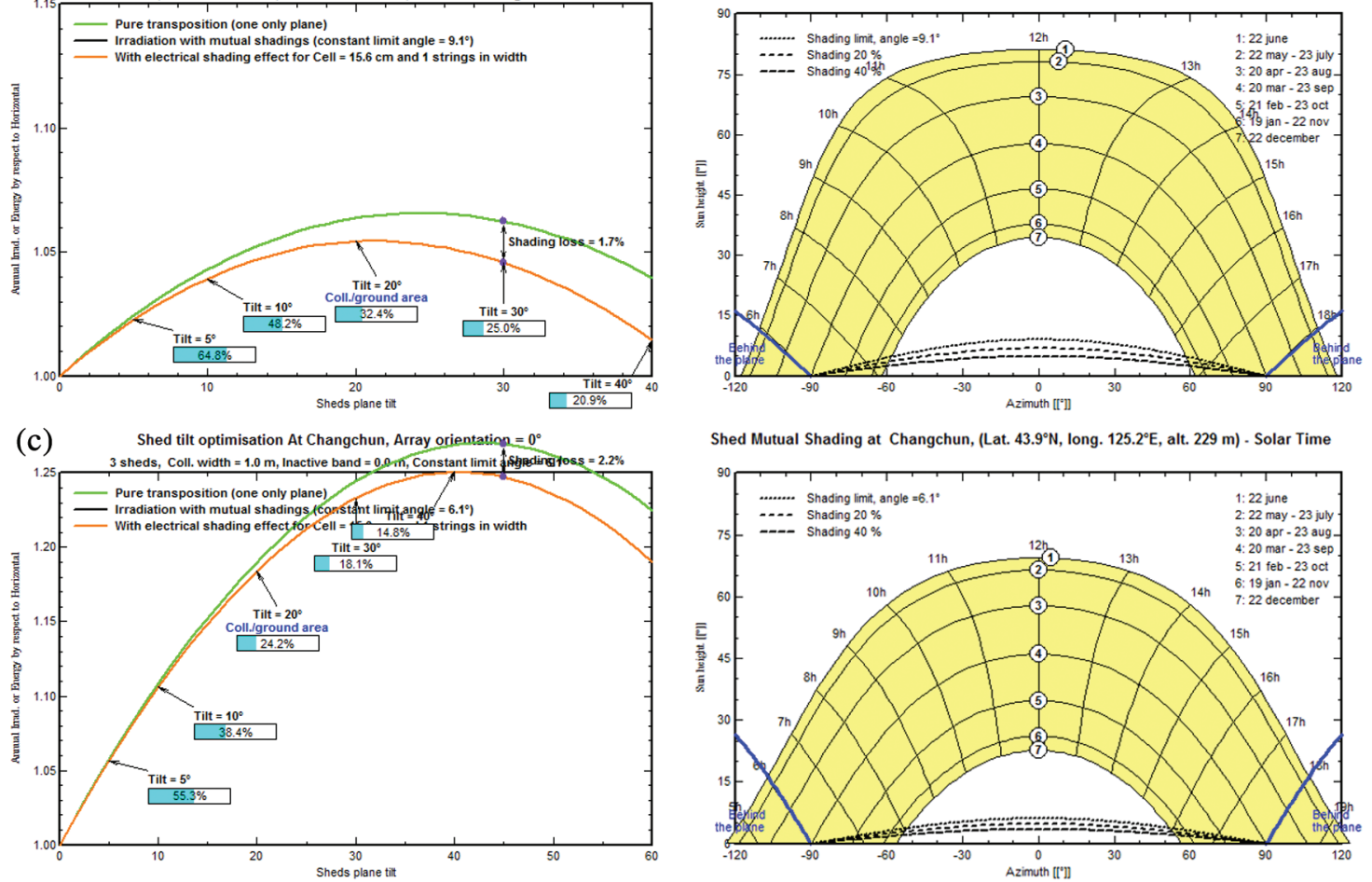

Shed Mutual Shading at Changchun, (Lat. $43.9^{\circ} \mathrm{N}$, long. $125.2^{\circ} \mathrm{E}$, alt. $229 \mathrm{~m}$ ) - Solar Time
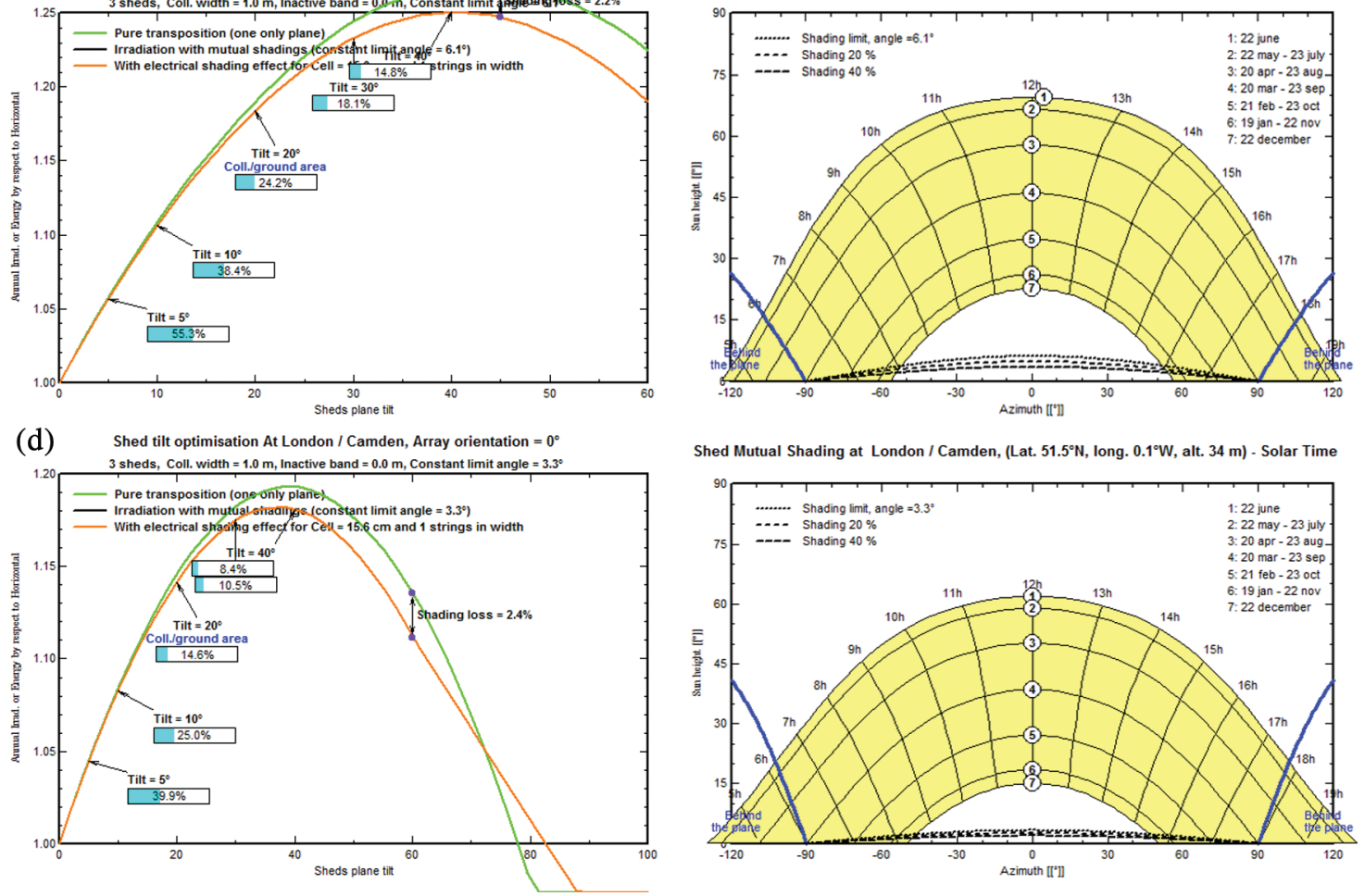

Shed Mutual Shading at London / Camden, (Lat. $51.5^{\circ} \mathrm{N}$, long. $0.1^{1} \mathrm{~W}$, alt. $34 \mathrm{~m}$ ) - Solar Time

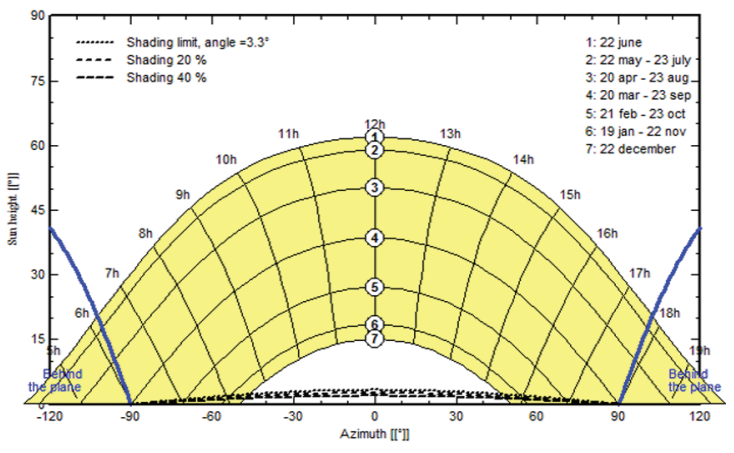

Figure 3: Schematic diagram of shading loss and sun shadow area of different areas. (a) Mexico City, (b) Xinyang, (c) Changchun, (d) London 


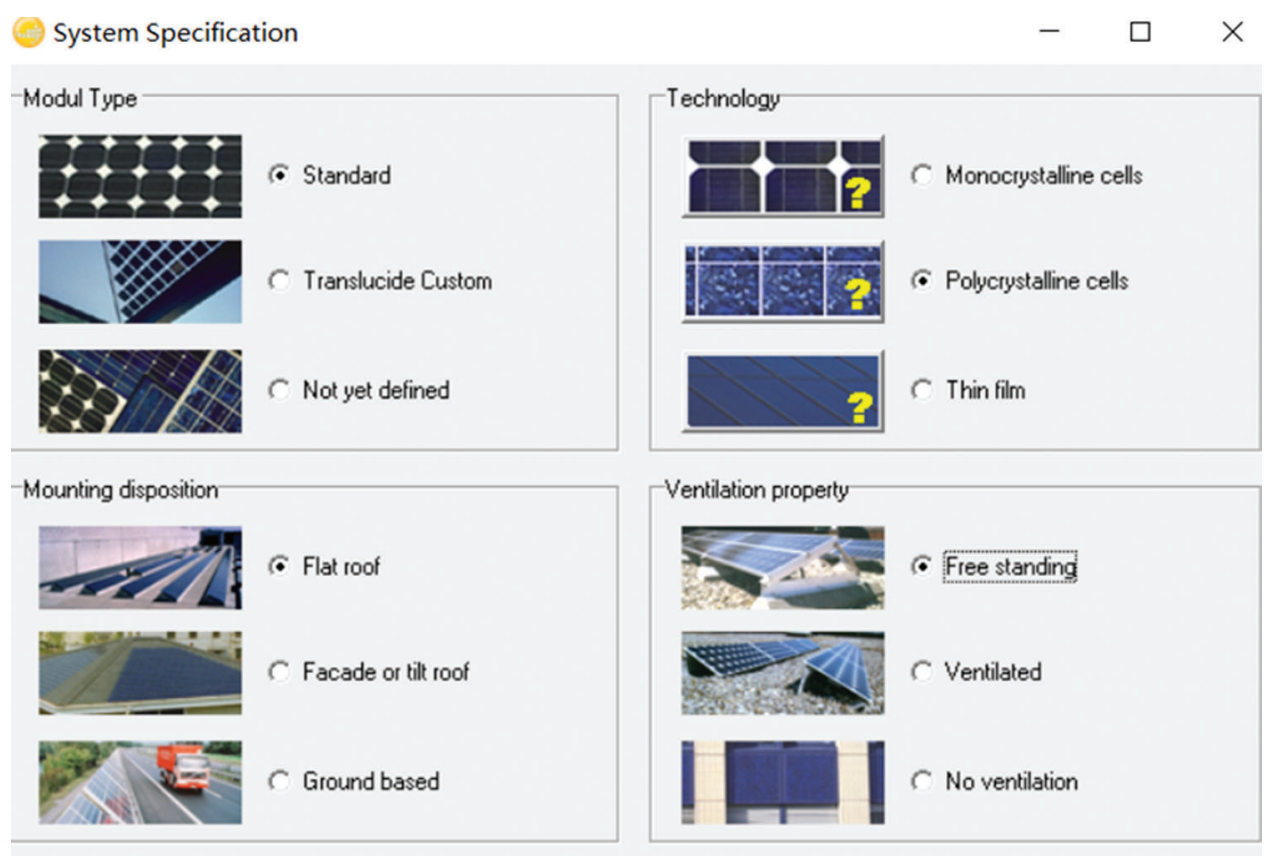

Figure 4: System specific settings

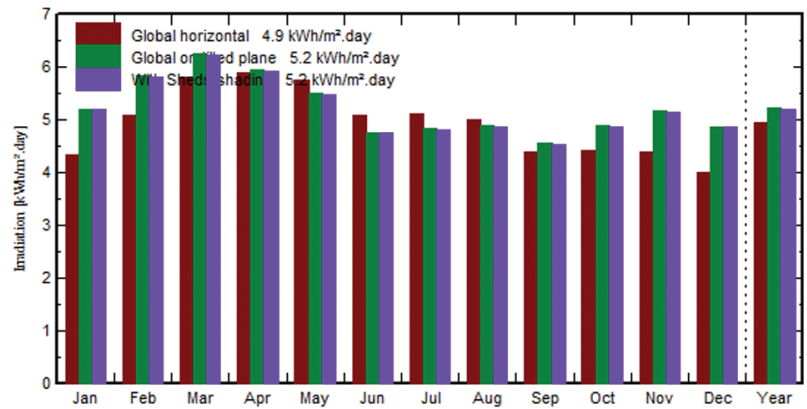

(a)

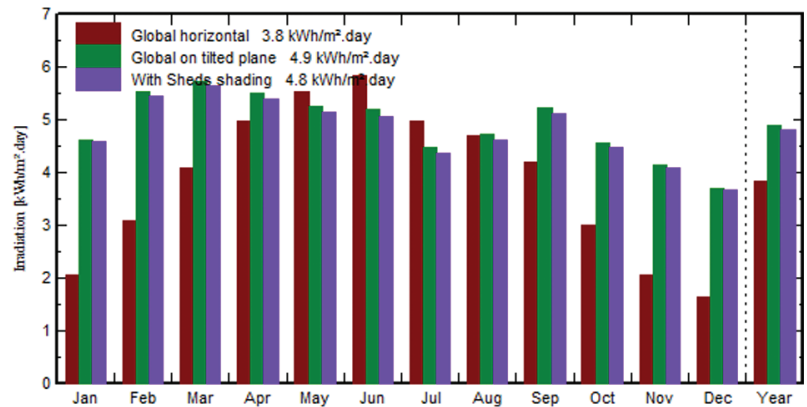

(c)

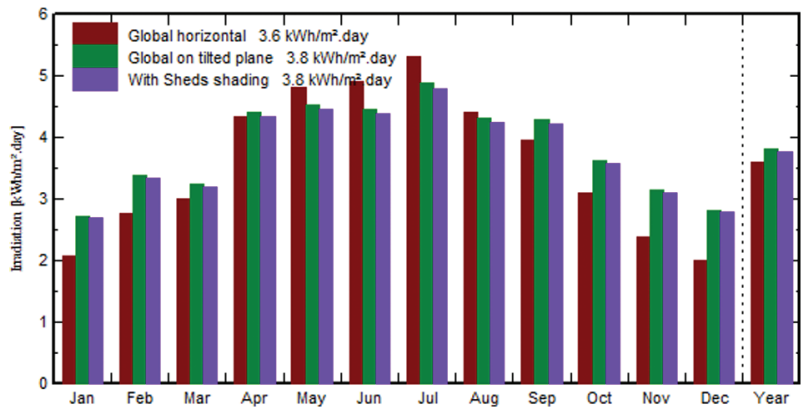

(b)

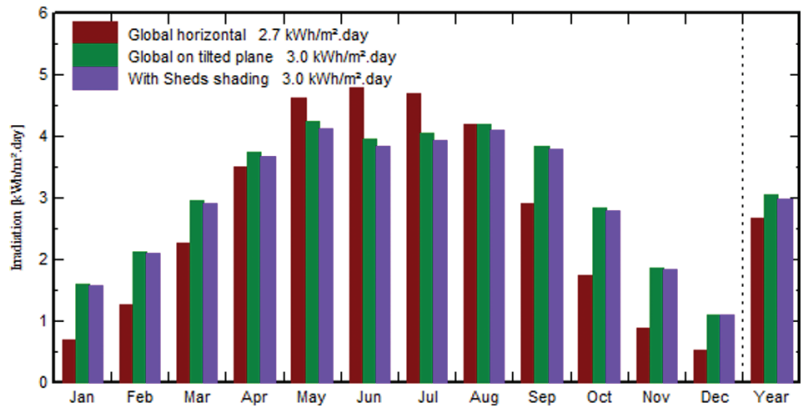

(d)

Figure 5: The average daily irradiation per unit area of each month and the whole year on the horizontal plane, the average daily irradiation per unit area of each month and the whole year on the corresponding tilted plane and the average daily irradiation per unit area of each month and the whole year after considering the shading loss of each region. (a) Mexico City, (b) Xinyang, (c) Changchun, (d) London 


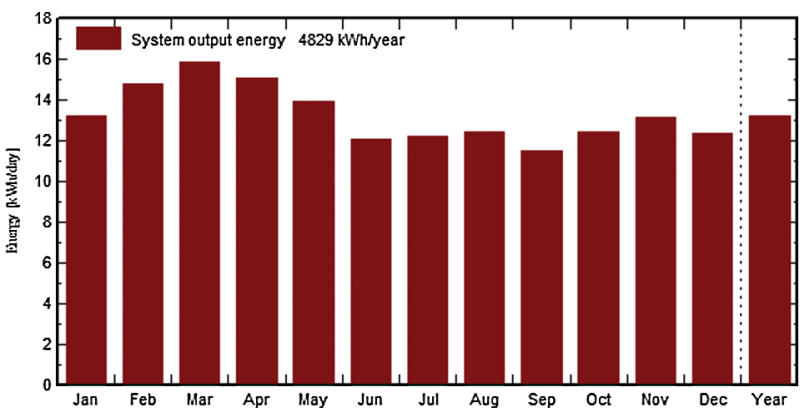

(a)

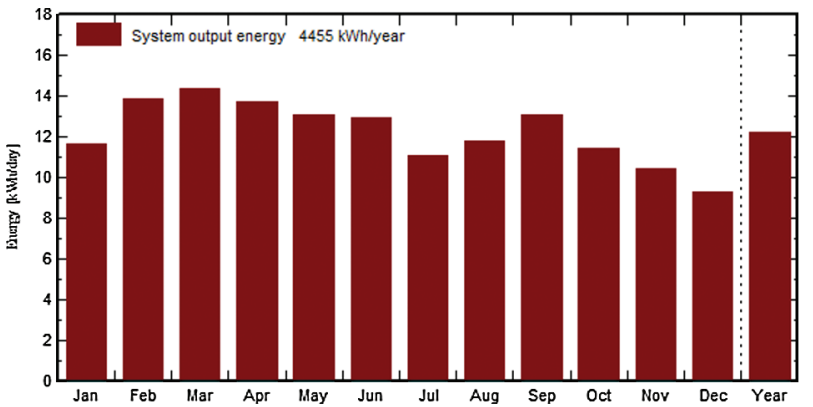

(c)

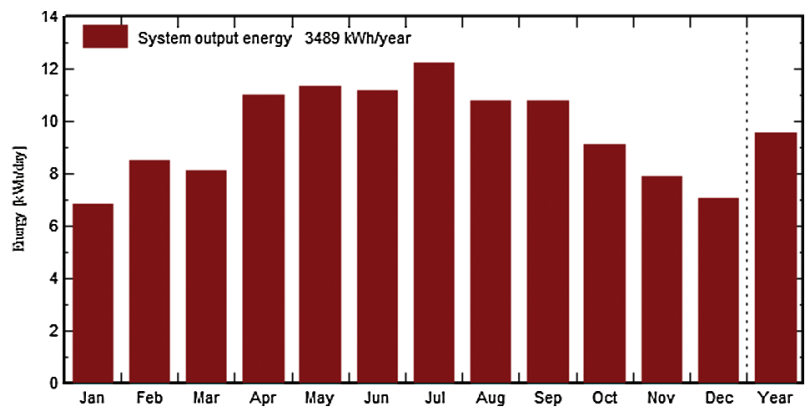

(b)

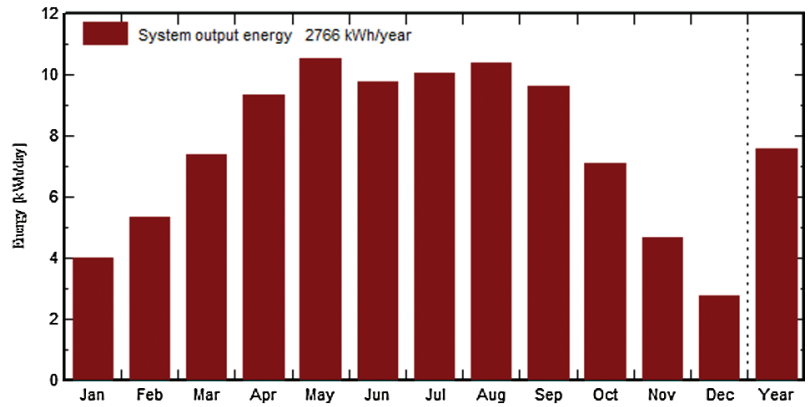

(d)

Figure 6: Monthly and annual average daily power generation and total power generation of different regions. (a) Mexico City, (b) Xinyang, (c) Changchun, (d) London

Table 2: Simulation results of four typical cities

\begin{tabular}{llllllll}
\hline No. & City & $\begin{array}{l}\text { Collector plane } \\
\left(\mathrm{kWh} / \mathrm{m}^{2} \text { day }\right)\end{array}$ & $\begin{array}{l}\text { Global horizontal } \\
\left(\mathrm{kWh} / \mathrm{m}^{2} \text { day }\right)\end{array}$ & $\begin{array}{l}\text { Shed shading } \\
\left(\mathrm{kWh} / \mathrm{m}^{2} \text { day }\right)\end{array}$ & $\begin{array}{l}\text { System output } \\
(\mathrm{kWh} / \text { day })\end{array}$ & $\begin{array}{l}\text { System } \\
\text { output }(\mathrm{kWh})\end{array}$ & $\begin{array}{l}\text { Solar energy utilization } \\
\text { efficiency }(\%)\end{array}$ \\
\hline 1 & $\begin{array}{l}\text { Mexico } \\
\text { City }\end{array}$ & 5.22 & 4.93 & 5.19 & 13.23 & 4829 & 14.91 \\
& & & & & & \\
2 & Xinyang & 3.81 & 3.59 & 3.70 & 9.44 & 3489 & 14.79 \\
3 & Changchun & 4.88 & 3.84 & 4.79 & 12.21 & 4455 & 17.66 \\
4 & London & 3.04 & 2.67 & 2.97 & 7.58 & 2766 & 15.77 \\
\hline
\end{tabular}

Based on these data, it could be found that:

a) The performance of photovoltaic system is mainly affected by radiation conditions;

b) The difference of simulation results is significantly different for different regions, because they have some relationships with optimum tilt angle and minimum spacing;

c) The solar radiation is different due to the different geographical location which also affects the power generation in different areas;

d) The proposed model and simulation results are consistent with the differences of power generation in different regions;

e) Due to the small energy loss and accurate setting of parameters for proposed system, the solar energy utilization efficiency of the proposed system has more efficient than large-scale photovoltaic power generation system.

Subsequently, Changchun as one of the four typical cities is chosen as the experimental area on the basis of the simulation results. 


\section{Experiment and Analysis}

\subsection{Experimental System}

The experimental system involves photovoltaic module, combiner box, touch screen, current collector, voltage collector, relay, invertor, controller, acquisition board, air switch, diode, emergency power supply and testing instrument.

The combiner box is designed with an anti-reverse diode and varistor which could realize the lightning protection. At the same time, the combiner box is installed in the outdoor and near the photovoltaic array.

The photovoltaic array of the experimental system consists of 12 standard polysilicon photovoltaic modules in series which is $3 \mathrm{~kW}$ capacity based on the simulation study. The optimal working voltage is $31.5 \mathrm{~V}$ and the generating power is $250 \mathrm{~W}$ for each photovoltaic module. 12 photovoltaic modules are placed in two rows and 6 photovoltaic modules are in one row. Changchun is chosen as the experimental area in this study according to the simulation results and the details of parameters could be found in Tab. 1. The specific placement of photovoltaic array is determined by geographical location of Changchun.

Fuse, air switch, relay, invertor, current collector, voltage collector, controller, acquisition board and other electrical components are used for the experimental test and protection which are shown in Fig. 7. The main function of the system control cabinet is applied to complete the data acquisition, power supply control and electrical equipment protection for the whole experimental system. The system control cabinet is equipped with controller, monitoring touch screen, invertor, collector and actuator. The system control cabinet is the "brain" to ensure the normal operation of the whole experimental system which is shown in Fig. 8.

The DC generated by the photovoltaic array enters the invertor through air switch and contactor. The invertor converts the DC into AC $220 \mathrm{~V}$ and controls the power supply through circuit breaker and AC contactor. The Voltage Collector for DC monitors the output voltage of the photovoltaic array, the current collector for DC monitors the output current of the photovoltaic array, the electric meter detects the power of the system and the fuse carries out over-current protection.

The collected signal is transmitted to the controller and communicated with the touch screen to realize the calculation and analysis. The experimental test and data acquisition are shown in Figs. 7 and 8.

\subsection{Results and Analysis}

The current collectors obtain the current value of photovoltaic array and the voltage collectors gain the voltage value of photovoltaic array respectively in this experiment. The data are collected and fed back on the touch screen which could be used for display and adjust the power supply status. I-V400 professional photovoltaic (solar) module and I-V characteristic analyzer are applied to test the volt ampere characteristic output of the photovoltaic system in this study. The results are shown in Fig. 9.

The curve is the relatively reasonable volt ampere characteristic curve (black line) and power output curve (blue line) of the photovoltaic system are more reasonable in Fig. 9. The results show that the overall performance of photovoltaic system is fine and there are no defect, hot spot, partial shading and damage. Therefore, this photovoltaic system could be put into real-time monitoring operation and data collection.

Touch screen is applied to monitor the operation of the whole experimental system. Current and voltage value of photovoltaic array, the instantaneous power generation and cumulative power generation of photovoltaic system could be acquired from the touch screen which could also control the working state of charging and discharging. The system parameters could be set and adjusted in time on the basis of the data displayed of the touch screen in this experimental test. Equation of cumulative power generation could be expressed: 


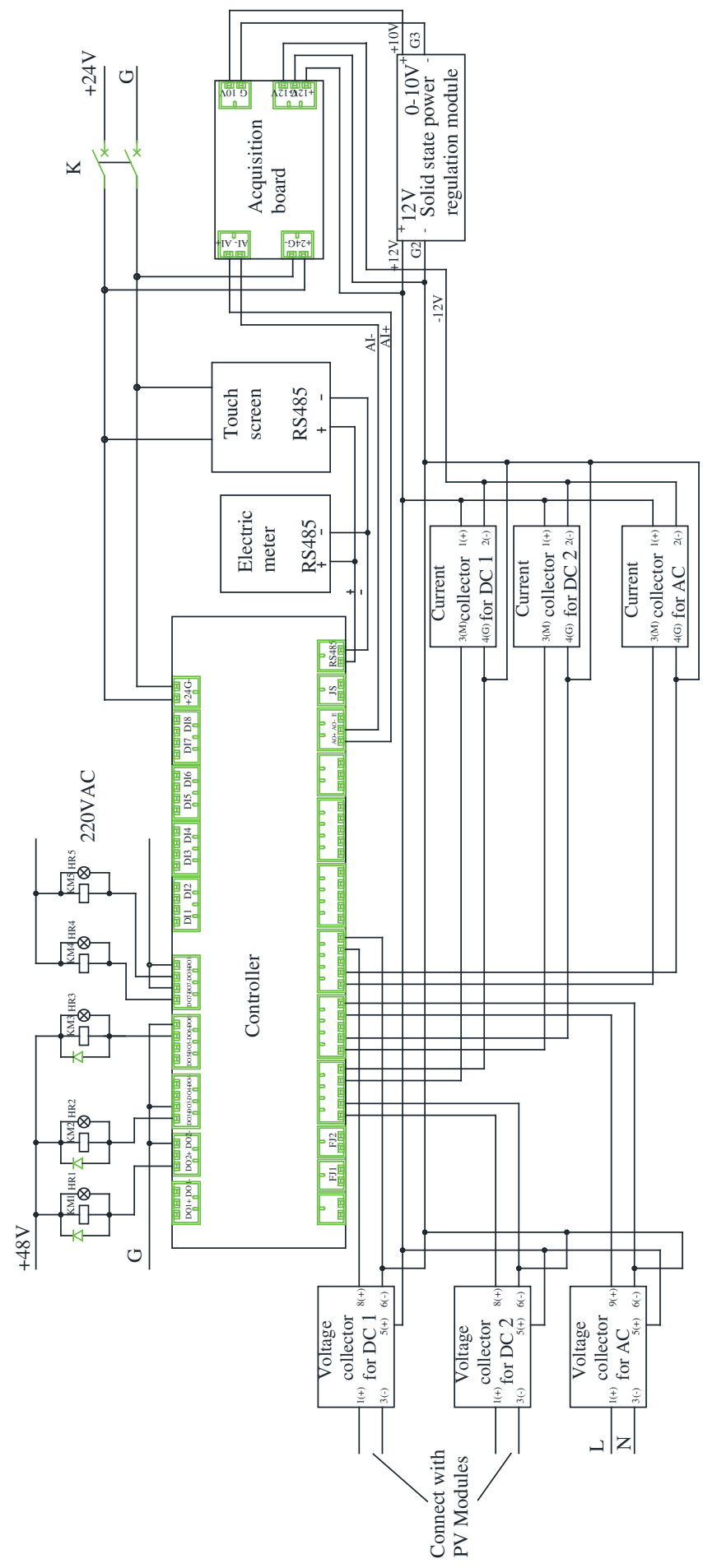

Figure 7: Schematic diagram of experimental test and data acquisition 


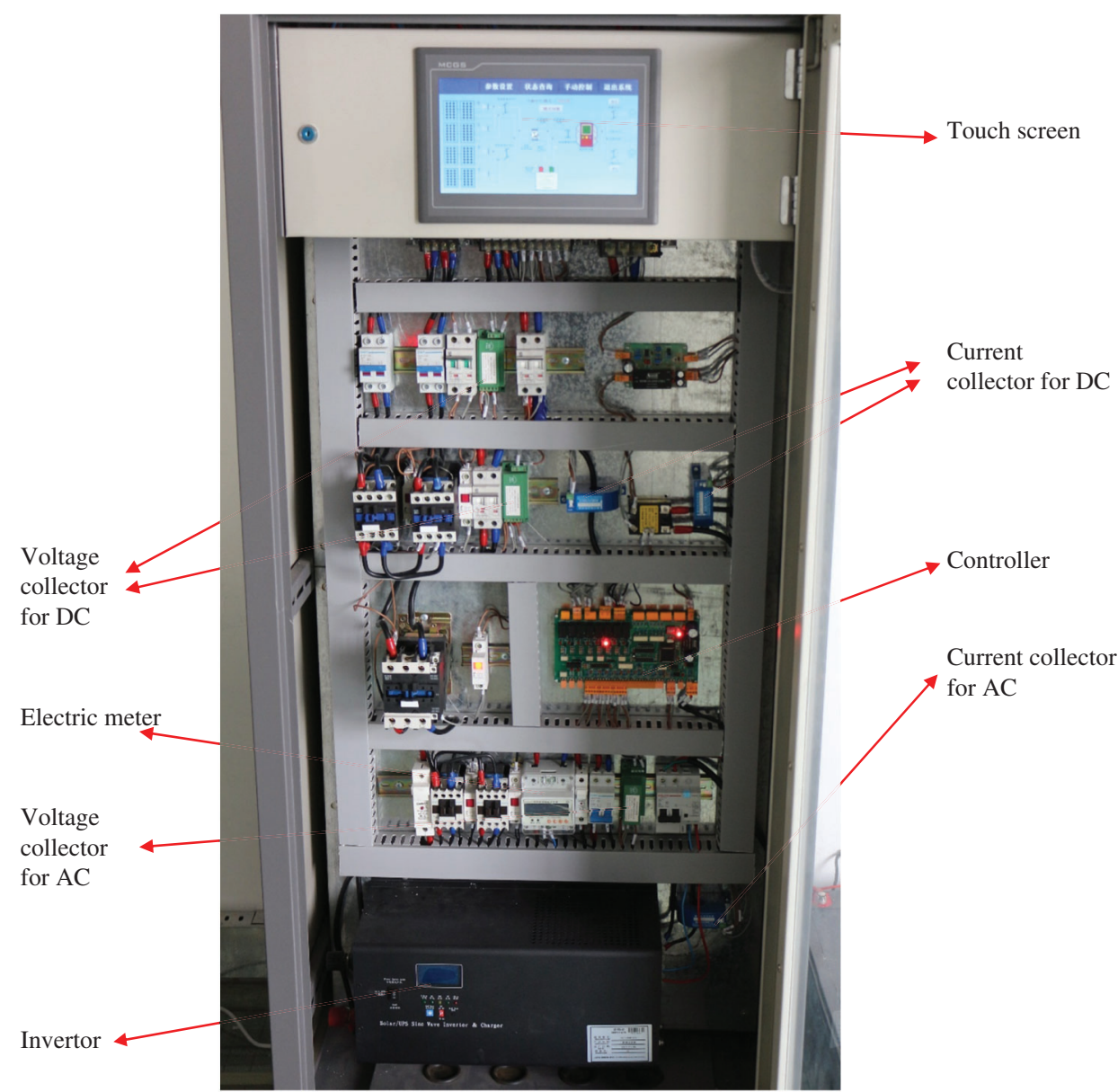

Note: The invertor could be used for inverter, voltage transformation, charging and filtering of emergency power supply in this experimental system.

Figure 8: Experimental test and data acquisition in the system control cabinet

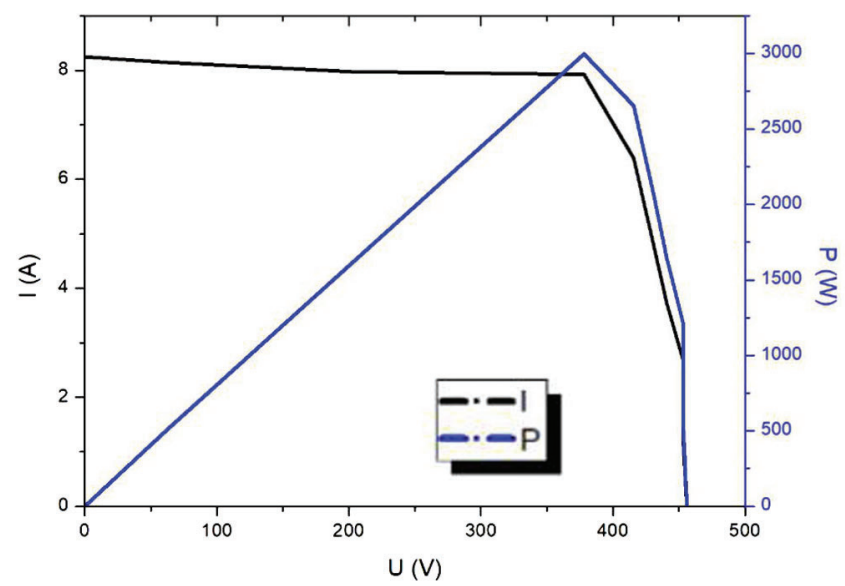

Figure 9: Volt ampere characteristic curve and power output curve of the photovoltaic system tested by the I-V400 
$E_{j}=\int_{0}^{j} u_{j} \cdot i_{j} \mathrm{~d} j$

where:

$E_{j}$ : Annual power generation of photovoltaic system, kWh;

$u_{j}$ : Instantaneous voltage of photovoltaic system, $\mathrm{V}$;

$i_{j}$ : Instantaneous current of photovoltaic system, A;

$j$ : Total operation time of photovoltaic system, $\mathrm{s}$.

According to the experimental results, Eq. (17) is applied to calculate the total power generation of this photovoltaic system. Finally, the total power generation of photovoltaic system is $4119 \mathrm{kWh}$ per year. There are some inevitably errors between the experimental results and the simulation results.

The relative error between simulation results and experimental results is $7.5 \%$ through calculation and analysis. The reasons for the relative error in this study are as follows:

a) Errors caused by measurement in the process of experimental test;

b) Errors due to the accuracy of the test instruments;

c) Optimum tilt angle is $45^{\circ}$ for the simulation study based on the PVsyst and $46^{\circ}$ for the experimental study on the basis of local conditions respectively.

These results confirmed that the simulation study could accurately predict the power generation of the proposed photovoltaic system and the experimental study verifies the conclusion of the simulation study in this research.

\section{Conclusions}

In order to carry out the optimization research and system evaluation of small-scale photovoltaic power system, the simulation research and experimental research are launched for different geographical location systems.

On the basis of the determination of photovoltaic model system, four typical geographical locations are selected and PVsyst is applied to the simulation work. The rated power of the photovoltaic system is $3 \mathrm{~kW}$, the optimum tilt angle of the four regions are set as $15^{\circ}, 30^{\circ}, 45^{\circ}$ and $60^{\circ}$ respectively, the width of the module is set as $1 \mathrm{~m}$, the vertical height of the module is set as $0.5 \mathrm{~m}$ and the minimum spacing of photovoltaic modules of four regions are set as 2.6, 4.0, 7.3, and 15.5, respectively in the simulation part. The simulation results show that the annual power generation is $4829 \mathrm{kWh}, 3489 \mathrm{kWh}, 4455 \mathrm{kWh}, 2766$ $\mathrm{kWh}$ and the solar energy utilization efficiency is $14.91 \%, 14.79 \%, 17.66 \%, 15.77 \%$ for Mexico City, Xinyang, Changchun and London respectively. These difference simulation results could be attributed to radiation conditions, optimum tilt angle, minimum spacing and different geographical locations.

The experimental study is carried out to demonstrate the simulation results subsequently. According to the conclusion of the simulation study, Changchun is chosen as the experimental area in this experiment. The rated power of the photovoltaic system, the width of the module, the vertical height of the module and the minimum spacing of photovoltaic modules are the same as the simulation study. The optimum tilt angle is set as $46^{\circ}$ according to the local condition which is similar to the simulation study. The experimental test and data acquisition are carried out after the establishment of the experimental system. The volt ampere characteristic curve and power output curve show that the photovoltaic system has no defects, hot spots, local shading and damage. The total power generation of photovoltaic system is $4119 \mathrm{kWh}$ per year. The relative error between simulation results and experimental results is $7.5 \%$ which is rational in this research. The experimental results confirm the validity of the simulation results. 
This study verifies that the application of small-scale PV systems should have a fully consideration for the geographical location and installation mode.

Funding Statement: This research was supported by Tianjin Technical Expert Project under grant 19JCTPJC43000; Science and Technology Planning Project of Jin Nan District Tianjin under grant 20190111; university-level research project of Tianjin Sino-German University of Applied Sciences under grant zdkt2018-001.

Conflicts of Interest: The authors declare that they have no conflicts of interest to report regarding the present study.

\section{References}

1. Krisada, P., Boonyang, P., Somchai, H. (2011). Design and construction of a mobile PV hybrid system prototype for isolated electrification. Procedia Engineering, 8, 138-145. DOI 10.1016/j.proeng.2011.03.025.

2. Mehmed, E., Erkan, D., Suat, S., Junseok, S., Suha, Y. et al. (2011). A mobile renewable house using PV/wind/fuel cell hybrid power system. Fuel and Energy Abstracts, 36(13), 7985-7992.

3. Amrita, R., Anand, K. (2017). Performance and economic analysis of a $27 \mathrm{~kW}$ grid-connected photovoltaic system in Suriname. IET Renewable Power Generation, 11(12), 1545-1554. DOI 10.1049/iet-rpg.2017.0204.

4. Rehman, S., El-Amin, I. (2015). Study of a solar PV/wind/diesel hybrid power system for a remotely located population near Arar, Saudi Arabia. Energy Exploration \& Exploitation, 33(4), 591-620. DOI 10.1260/01445987.33.4.591.

5. Song, J., Choi, Y. (2016). Analysis of the potential for use of floating photovoltaic systems on mine pit lakes: case study at the SsangYong open-pit limestone mine in Korea. Energies, 9(2), 102. DOI 10.3390/en9020102.

6. Chen, L., Wang, J. D., Xu, C. X. (2019). The application of solar photovoltaic power generation system in ships. Energy Exploration \& Exploitation, 94(S1), 525-529.

7. Yang, J., Ma, X. Y. (2019). Ship power generation system model based on distributed solar photovoltaic power generation. Energy Exploration \& Exploitation, 94(S1), 520-524.

8. Khoo, Y. S., Nobre, A., Malhotra, R., Yang, D., Ruther, R. et al. (2014). Optimal orientation and tilt angle for maximizing in-plane solar irradiation for PV applications in Singapore. IEEE Journal of Photovoltaics, 4(2), 647-653. DOI 10.1109/JPHOTOV.2013.2292743.

9. Mark, Z. J., Vijaysinh, J. (2018). World estimates of PV optimal tilt angles and ratios of sunlight incident upon tilted and tracked PV panels relative to horizontal panels. Solar Energy, 2018(169), 55-66.

10. Yadav, S., Panda, S. K., Tripathy, M. (2018). Performance of building integrated photovoltaic thermal system with PV module installed at optimum tilt angle and influenced by shadow. Renewable Energy, 2018(127), 11-23. DOI 10.1016/j.renene.2018.04.030.

11. Sunderan, P., Ismail, A. M., Singh, B., Mohammed, N. M. (2011). Optimum tilt angle and orientation of standalone photovoltaic electricity generation systems for rural electrification. Journal of Applied Sciences, 11(7), 1219-1224. DOI 10.3923/jas.2011.1219.1224.

12. Kuvshinov, V. V., Abd Ali, L. M., Kakushina, E. G., Krit, B. L., Morozova, N. V. et al. (2019). Studies of the PV array characteristics with changing array surface irradiance. Applied Solar Energy, 55(4), 223-228. DOI 10.3103/ S0003701X19040054.

13. Tobón, A., Peláez-Restrepo, J., Montano, J., Durango, M., Herrera, J. et al. (2020). MPPT of a photovoltaic panels array with partial shading using the IPSM with implementation both in simulation as in hardware. Energies, 13(4), 815. DOI 10.3390/en13040815.

14. Zhang, P., Sui, H. (2020). Maximum power point tracking technology of photovoltaic array under partial shading based on adaptive improved differential evolution algorithm. Energies, 13(5), 1254. DOI 10.3390/en13051254.

15. Sauer, K. J., Roessler, T., Hansen, C. W. (2015). Modeling the irradiance and temperature dependence of photovoltaic modules in PVsyst. IEEE Journal of Photovoltaics, 5(1), 152-158. DOI 10.1109/JPHOTOV.2014.2364133.

16. Odeh, S. (2018). Thermal performance of dwellings with rooftop PV panels and PV/thermal collectors. Energies, 11(7), 1879. DOI 10.3390/en11071879. 
17. Purohit, I., Purohit, P. (2018). Performance assessment of grid-interactive solar photovoltaic projects under India's national solar mission. Applied Energy, 222, 25-41. DOI 10.1016/j.apenergy.2018.03.135.

18. Zhang, L., Chen, Z. J. (2017). Design and research of the movable hybrid photovoltaic-thermal (PVT) system. Energies, 10(4), 507. DOI 10.3390/en10040507.

19. Zhang, L., Cao, B. (2018). Design and analysis of a floor radiant heating system based on energy substitution technology. Applied Sciences, 8(4), 491. DOI 10.3390/app8040491.

20. Zhang, L., Chen, Z. J., Wang, L. (2018). Evaluating the energy-saving potential of solar dedicated ventilation systems based on ADRC. Applied Sciences, 8(11), 2328. DOI 10.3390/app8112328. 